\title{
Creativity in Virtual Teams: A Review and Agenda for Future Research
}

\author{
Roni Reiter-Palmon1, William Kramer1, Joseph A. Allen2, \\ Vignesh R. Murugavel1, and Salvatore A. Leone1 \\ 1 Department of Psychology University of Nebraska at Omaha, USA \\ 2 Department of Family and Preventive Medicine, University of Utah Health, USA
}

\section{ABSTRACT}

As communication technology capabilities have improved and the globalization of the workforce has resulted in distributed teams, organizations have been shifting towards virtual teams and virtual meetings over the last decade. This trend has been accelerated with current work-from-home orders due to COVID-19. Even though virtual collaboration has, in the past, been the focus of multiple studies, there are some surprising gaps in our knowledge. For instance, there are few empirical studies examining the impact of virtual devices and tools on creative problem-solving. While there is a substantial body of research on electronic brainstorming and the use of virtual tools for idea generation, less is known about earlier processes such as problem construction or later processes such as idea evaluation and idea selection. Furthermore, as a dynamic process, creativity and innovation is heavily influenced by the people engaged in the process and their collaborative environment, yet there is a gap in the literature regarding the type of virtual tools used in the process (i.e., audio + video vs. audio alone, or the use of file-sharing technologies). In this paper, we will review the current literature on virtual teams, virtual meetings, and creativity. We will then explore theoreti-
\end{abstract}

cal frameworks such as media richness theory that can help us understand how virtuality and virtual tools may influence team creativity across the dynamic range of the creative problem-solving process. Finally, given the limited research in the domain of virtual team creativity we provide questions to help guide future research. Research questions will help identify those areas where virtual teams may be beneficial for creativity and areas where virtual teams may be likely to perform less effectively on creative tasks.

\section{KEYWORDS:}

Creativity, innovation, teams, virtual teams

\section{Article history:}

Received: May 1, 2021

Received in revised from: June 29, 2021

Accepted: July 1, 2021

ISSN 2354-0036

DOI: 10.2478/ctra-2021-0011

\section{Corresponding author at:}

Roni Reiter-Palmon

E-MAIL: rreiter-palmon@unomaha.edu 


\section{CREATIVITY IN VIRTUAL TEAMS: A REVIEW AND AGENDA FOR FUTURE RESEARCH}

In the last few decades, technology use and its integration into the workplace has increased and has become ubiquitous. This development has introduced unforeseen complexities that extend from everyday tasks to the organization as a whole. One such effect is the ease with which technology has allowed geographically-distant employees to collaborate with others to achieve shared goals (Cascio, 2000; Kanawattanachai \& Yoo, 2002). As of the year 2016, researchers found that $85 \%$ of employees worked in at least one virtual team, with nearly half (41\%) never meeting in person (CultureWizard by RW3, 2016). These teams require a virtual medium to facilitate the communication and collaboration processes that occur during meetings, a shift that had a marked impact on team dynamics and team cognition and creative performance (White, 2014). The trend towards virtualization has accelerated with the emergence of COVID-19 as many organizations moved to remote work, and employees saw a large increase in virtual medium use. Indeed, in the first month after quarantine, Microsoft Teams reported a 100\% increase in usage (Microsoft, 2020). A recent survey showed that the average worker went from having about $4 \%$ of their total meetings in a virtual format to having $60 \%$ or more virtually (Reed \& Allen, 2021). Further, several organizations have indicated that they will likely keep some or most of the workforce working remotely. A recent report by Mckinsey indicated that $49 \%$ of jobs could be done remotely for at least one day a week, and $22 \%$ of jobs remote for the majority of the week. Finally, a desire to work from home has emerged among many employees, as evidenced in a recent survey. The survey found that $75 \%$ of respondents would prefer working from home or a hybrid workplace, and onethird reported that they would consider finding a new job if required to go back to working in an office full time (Robert Half, 2021). Over the past few years, the need to switch to virtual forms of communication has revealed advancements in the capabilities of technology. Organization have begun to recognize the benefits of virtual work including the ability to engage in teamwork anywhere, anytime, and with just about anyone. Changing management views on virtual work has highlighted the need to further study virtual teams.

Before proceeding, it is important to clearly define what we mean by virtual work, virtual teams, and virtual meetings. In this article, we refer to virtual work as any type of work that is electronically mediated and often represents material work (Robey, Schwaig, \& Jin, 2003). For example, the writing of manuscripts for a journal often occurs in a fully electconic medium between coauthors, and some journals never publish in print. In this sense, involved parties are reliant upon a virtual medium to complete their tasking. Virtual teams, while similar, refer to teams whose members engage in interdependent tasks while geographically dispersed (Allison, Shuffler, \& Wallace, 2015). For example, a global marketing team that comes together to unify their approach to marketing in multiple countries and markets. In this sense, virtual teams broaden the focus from being solely on the work or task itself and include the nuance of teamwork behaviors such as managing interpersonal relationships and coordinating interdependently. Finally, virtual meetings 
are workplace meetings that occur via video or audio means, often within an online platform, and where participants are not collocated (Allison et al., 2015; Reed \& Allen, 2021). Such meetings inherently involve communication between team members and, as such, can promote engaging in virtual teamwork behaviors that lead to virtual work completion.

With these definitions in mind, globalization and increasingly competitive markets have prompted organizations to value novel and unique solutions and products that enable virtual work, teaming, meeting, and collaboration (Shalley \& Gilson, 2004). Given that an increasing number of employees work as part of a virtual team, understanding how virtuality will influence creativity is important. Existing research shows that the process of creativity can be challenging for many faceto-face teams (e.g., Harvey, 2014; Reiter-Palmon, 2018; Taggar, 2019). However, overlaying a virtual medium raises several unique challenges centered on the task itself as well as the social processes that occur in the virtual space. Currently, only limited research has explored a team's creative process in a virtual medium. As the trends towards globalization have only increased in recent years, understanding work in virtual mediums is key for future explorations.

Conversely, a large body of research has examined the effects of communication modalities such as the use of voice only or audio-visual communication in the context of group communication and collaboration (Dennis \& Kinney, 1998; Marlow et al, 2017). Considering the massive shift in the more common modalities of meetings due to both the COVID-19 pandemic and the recovery process, even the recent work noted here is dated in terms of the impact of modality on various meeting processes (Reed \& Allen, 2021). In fact, even before COVID-19, there was a dearth of research examining the impact of communication modalities on creativity in virtual teams and their subsequent effect on team performance.

\section{TEAM CREATIVITY AND INNOVATION}

In the last two decades, interest in creativity and innovation has grown tremendously, with research finding that both are important for organizational performance (Dess \& Pickens, 2000; Mumford \& Hunter, 2005; Shalley et al., 2004). Organizational success has become predicated on rapid change and adaptation in innovation-driven work environments. Paired with the rising use of teams (Kozlowski \& Bell, 2008), organizations have moved away from a hierarchical and static structure to a more dynamic, team-oriented, and cross-functional structure (Kozlowski \& Bell, 2008; Shalley et al., 2004; Reiter-Palmon et al., 2011).

It is important at this point to define what is meant by team creativity and team innovation. Creativity has typically been defined by focusing on the creative product. Specifically, creativity has been defined in terms of the production of a "novel product, idea, or problem solution that is of value to the individual and/or the larger social group" (Hennessey \& Amabile, 2010, p. 572). However, there is some variation in how researchers define creativity in relation to innovation. Some use these terms interchangeably. Others suggest that creativity involves the generation of 
ideas, whereas innovation includes both idea generation and implementation (Anderson, De Dreu, \& Nijstad, 2004). Finally, others suggest that creativity is viewed as the generation of ideas and solutions, whereas innovation is defined as the implementation of these ideas and solutions in the organization (Anderson, Potocnik, \& Zhou, 2014; West, 2002). Anderson et al. (2014) define creativity and innovation at work as the following:

\footnotetext{
the processes, outcomes, and products of attempts to develop and introduce new and improved ways of doing things. The creativity stage of this process refers to idea generation, and innovation refers to the subsequent stage of implementing ideas toward better procedures, practices, and products. Creativity and innovation can occur at the level of the individual, work team, organization, or at more than one of these levels combined, but invariably result in identifiable benefits at one or more of these levels of analysis (p. 2).
}

While Anderson et al. (2014) provide a differentiation between creativity and innovation, this approach has not been adopted by all researchers in this space. Further, the definition as it is presented here focuses on idea generation, and no (or limited) attention is given to processes that occur prior to that such as problem identification and construction (Reiter-Palmon, 2018). Further, innovation has typically been associated with tangible organizational outcomes, whereas creativity may or may not require such outcomes. We therefore include both creativity and innovation in our discussion to allow the reader to dertermine which term they prefer.

\section{MEDIA RICHNESS IN VIRTUAL ENVIRONMENTS}

One way in which communication modalities in both face to face and virtual environments have been evaluated is by the richness of the cues they provide. Richness represents the ability of different media to convey information based on the inherent characteristics of the media. The richer the communication media, the more visual and verbal cues provided in transmitting information between the sender and receivers (Daft \& Lengel, 1986).

According to media richness theory, cues such as visible facial expressions and auditory intonation allow a sender to make their meaning clear (Daft \& Lengel, 1986). Uncertainty and equivocality (i.e., misinterpretation) on the part of the receivers of the communication is reduced as a result. For instance, an individual using a teleconferencing software would be able to draw from auditory social cues such as loudness and pitch to draw inferences regarding the affective state of his or her teammates (Andriessen, 2003). A videoconferencing software, on the other hand, offers both auditory and visual cues, such as non-verbal behaviors, to present a more comprehensive picture of a teammate's state (Driskell, Radtke, \& Salas, 2003). In some cases, a lack of said social cues can make teammates feel as if they are not socially connected. Research has found that this disconnection can lead to negative outcomes, such as reduced information sharing and limited communication of novel information and ideas (Hogg \& Reid, 2006). 
Receivers and senders both benefit when a media provides additional contextual information to a message, as the likelihood of receiver misinterpretation decreases. For example, a humorous or sarcastic statement may be misconstrued as a demand over text, whereas a video message will provide the appropriate non-verbal cues to avoid ambiguity. According to this theory, richer communication modalities are expected to lead to increased task performance in creativity in particular (Suh, 1999; Rice, 1992). Richer media (containing visual and verbal cues) should reduce ambiguity related to tasks required for creativity among individuals in a virtual team. More specifically, as the richness of virtual team communication modality increases from lean texting to audio to video conferencing, performance on the progression of tasks requiring a creative solution should likewise increase.

In addition, communication modality can influence social processes that are associated with effective team performance. Among virtual teams who use a less rich communication modality, important team processes, such as the establishment of trust and psychological safety, will likely take significantly longer to emerge, if at all (Jarvenpaa \& Leidner, 1999; Bos et al., 2001). This delay or loss can cause a virtual team member to feel less connected to fellow members and therefore decrease collective efficacy (Staples \& Webster, 2008). Among communication modalities that offer a richer environment, teammates can more easily associate with one another, share successes, and develop a shared identity (Bowers et al., 2008). For these reasons, it is important to not only consider the differences between face-to-face and virtual teams, but also compare findings across the spectrum of media richness for virtual teams.

This spectrum of media richness has moved beyond the modalities of text, audio, and video. Current communication platforms (i.e., Zoom, Slack, Microsoft Teams) allow for a more hybrid interaction approach. These platforms offer multiple, simultaneous methods of communication like comments in text form, private side conversation (text that is only visible to one person) or sharing of information via documents or graphics. In addition, some platforms offer team members the ability to annotate virtual documents simultaneously in real-time. For example, Zoom provides a virtual collaborative whiteboard option for meeting attendees to use. All of these functions operate in conjunction with the ongoing audio or video component, thus adding to the richness of the information conveyed. Media Richness Theory in its original form did not account for these different additional information sources (Jarvenpaa \& Keating, 2021).

Moreover, Media Richness Theory in its original form did not anticipate the rise of lean communication modalities that enhance user interactivity (Ishii et al., 2019). For example, GoogleDocs may traditionally be considered a lean modality due to a lack of verbal, social, or facial cues that can provide richness and context to communication. According to Daft and Lengel (1986), such modalities are expected to be associated with both increased communication misunderstandings and time to complete tasks. However, empirical research suggests highly effective teams leverage the significant effect of interactivity occurring within lean modalities (Aritz et al., 2018). Aritz and colleagues argue that tools embedded within lean media (e.g., instant messaging, commenting, file sharing, external web linking, etc.) allow teams to coordinate their efforts, refine their work 
outputs, and complete tasks effectively. Similarly, Kwak (2012) argued that media may contain elements of both leanness and richness. In the example of GoogleDocs, the platform provides workers with access to parallelism (i.e., instant feedback), higher degrees of rehearsability (i.e., processing/refinement of work outputs), reprocessability (i.e., the ability to reaccess/archive past communication), and the capability to work both synchronously (i.e., simultaneously) and asynchronously (i.e., nonconcurrently).

Indeed, the synchronicity of work is a significant concern for disparate virtual teams (Kirkman \& Mathieu, 2005). Media Richness Theory traditionally implies rich forms of communication (e.g., face-to-face) provide high levels of parallelism, and thus may lead to greater team effectiveness. Rich communication technology such as videoconferencing may also overcome constraints associated with time, space, or the cost of face-to-face meetings. However, certain practical concerns for virtual teams such as differing time zones, scheduling, or preferences in working hours can hinder the appropriateness of rich communication modalities (O'Leary \& Cummings, 2007). In contrast, lean communication modalities may address the limitations of time, information, and geography. Thomas (2013) demonstrated that email usage was significantly associated with increased knowledge sharing and effectiveness during the development of new products. Thomas argued that rich forms of communication (e.g., videoconferencing) require high-degrees of coordination among virtual workers, increased time investment, and do not facilitate the identification of fast solutions compared to lean modalities such as email. Ultimately, Thomas recommends that virtual workers take advantage of both rich and lean communication tools to develop new products and solve work-related problems.

The variety of communication options in modern virtual meeting platforms calls for expanding the study of media richness. Unpacking the many factors that can influence media richness may provide a better understanding of how virtual teams tackle complex and ambiguous problems and solve them creatively. However, in order to address the effects of media richness on creativity, it is important to understand the core processes on creative problem solving.

Team Creative Cognition. Previous team creativity research has largely focused on evaluating the role of the creative individual as part of the team (Taggar, 2002). This research has provided critical insight regarding the relationships among specific team variables (e.g., team diversity), team social processes (e.g., conflict), and social cognitive processes (e.g., shared mental models), in terms of their impact on individual-level team members (Hulsheger et al., 2009). As a result, there is an established stream of research that has informed our understanding of social and emergent team processes associated with creativity (Hulsherger et al., 2009). However, researchers have only begun to attend to the factors that influence team-level creativity as a construct, as opposed to individual creativity within the team context (Hulsherger et al., 2009; Reiter-Palmon \& Harms, 2017).

Factors that influence team creativity focus not only on the individual level, but also on teamassociated elements such as emergent states and processes (Reiter-Palmon \& Paulus, 2020). While many factors may influence creative problem-solving (e.g., leadership, personality characteristics, 
motivation, goals, etc.), creative problem-solving cognitions have emerged as an important facet of both individual and team creativity (Reiter-Palmon et al., 2008). Currently, the cognitive processes underlying creativity have received more attention at the individual than the team level (ReiterPalmon et al., 2008). While there are multiple models that focus on creative problem solving at the individual level (Mumford et al., 1991; Sternberg, 1988; Ward et al., 1999), work on the cognitive processes associated with creative problem solving in teams, with the exception of idea generation, has been lagging (Reiter-Palmon et al., 2008; Reiter-Palmon et al., 2011). Core processes that occur before or after idea generation, such as problem identification and construction and idea evaluation and selection, have received much less attention, especially at the team level (ReiterPalmon, 2018).

One important difference between individual-level models and team creative cognition models is that, at the team level, there is an additional layer of team dynamics (Reiter-Palmon et al., 2020). While individuals engage in cognitive processes, additional factors must play a role for the processes to engender team-level creative outcomes. That is, individuals must share their thoughts and cognitions, requiring communication and information sharing (Cooke, 2015; ReiterPalmon, 2018). Further, social processes such as conflict, cohesion, trust, and psychological safety can influence both individual-level cognition and the sharing of information in teams (De Dreu et al., 2011), resulting in direct effects on team creativity and innovation. These communication and social processes can be directly affected by the virtual environment and the richness of the cues provided by the communication. When discussing individual and team-level cognition, three main processes have been studied, specifically problem construction, idea generation, and idea evaluation (Reiter-Palmon et al., 2018).

Problem Construction. During the problem construction process, the problem solver recognizes that there is a problem to be solved, defines the parameters of the problem, and constructs the problem (Reiter-Palmon \& Robinson, 2009). Therefore, problem construction includes both the identification of the problem by the problem solver and the structuring of the problem, which guides the subsequent problem-solving effort. Thus, the problem construction process clarifies and reduces some ambiguity presented by complex and ill-defined problems that often confront individuals and teams. At the individual level, problem identification and construction has been found to facilitate creative problem solving (Abdulla et al., 2020; Arreola \& Reiter-Palmon, 2016; Ma, 2009; Reiter-Palmon et al., 1997; Vernon \& Hocking, 2016). At the team level, research on problem identification and construction has focused on whether team members agree on how to define and construct the problem (Cronin \& Weingart, 2007).

Research indicates that creative teams suffer when the problem frameworks vary across team members, and the goal states identified through problem construction cannot be reconciled in a single solution (Goh et al., 2013; Weingart et al., 2005). However, other research has suggested that when leaders and teams identify the discrepancies and resolve them in a constructive way, differences actually may increase team creativity (Leonardi, 2011; Gish \& Clausen, 2013; Reiter- 
Palmon \& Murugavel, 2018; Weingart et al., 2008). This was especially true for interdisciplinary teams where team members are more likely to have diverse perspectives regarding the problem (Toader et al., 2019; Toader \& Kessler, 2018). However, to our knowledge, no research has evaluated problem identification and construction in virtual teams. Future research needs to evaluate problem identification and construction not only in face to face teams but also in virtual teams.

Constraints and restrictions placed on the solution have also been found to be important for effective problem identification and construction (Medeiros et al., 2017; Mumford et al., 1994). While constraints typically are framed as opposed to the freedom that is needed and associated with creativity (Caniels \& Rietzschel, 2015), current research suggests that it can also have beneficial effects (Haught-Tromp, 2016; Medeiros et al., 2017). A famous example of constraints and the positive effects of constraints is that of the book Green Eggs and Ham, written by Dr. Seuss. Dr. Seuss was challenged by his publisher to write a children's story that included only 50 words or less. This challenge resulted in a creative outcome in the form of a book.

Rosso (2014) suggested that for teams, two types of constraints emerge. Process constraints focus on how the work is done and include factors such as time, equipment, technology, money, and personnel. Outcome constraints focus on the expected product, including factors such as markets, consumers, product requirements, and business needs. Both could serve as either facilitators or inhibitors of creativity. Specifically, process constraints tended to inhibit team creativity when they reduced experimentation and intrinsic motivation as a result of the perception that they reduced possibilities. Alternatively, process constraints could increase creativity when the team was motivated and cohesive. Product constraints tended to enhance motivation when they provided structure and a common framework but tended to inhibit creativity when they encouraged staying on the same course and the status quo. However, team dynamics were also important in how teams reacted to constraints. When teams had positive interactions, collaboration, and effective leadership, constraints facilitated creativity. When interactions were of poor quality, communication and collaboration suffered, and when team leadership was not effective, creativity was inhibited. Because the Rosso study was conducted with teams that met face to face, the generalizability of these findings to virtual teams is not well understood. Although virtual teams may encounter similar constraints to those experienced by face-to-face teams, constraints for virtual teams may have a more pronounced or have different influences on creativity. Issues that are more prevalent in virtual teams and may be part of the process constraints were not discussed in Rosso (2014). For example, the limiting social cues in virtual media may be part of the process constraints.

The research conducted indicates that communication and sharing of information are important mechanisms by which teams reach a shared understanding of the nature of the problem, and may resolve discrepancies in problem identification and construction (Reiter-Palmon et al., 2008; Reiter-Palmon \& Sands, 2015). For a creative solution to emerge, however, teams must find a way to combine and integrate these divergent problem representations beyond simple compromise or conformity for the sake of expediency (Mesmer-Magnus \& DeChurch, 2009; Reiter-Palmon, 2018; Weingart et al., 2008). Virtuality is likely to affect team problem identification and construction by 
influencing both individual-level cognition, as well as the social processes associated with effectively performing this process within a team. The effects of virtuality and media richness on problem identification and construction can take multiple forms. For example, as a result of virtuality, teams may be able to invite experts from different geographical location and be able to consult with a variety of subject matter experts. In this case, virtuality may enhance a more comprehensive and complex understanding of the problem, which will likely increase creativity. On the other hand, virtuality, especially when media richness is low, may limit communication, reduce trust, and increase misunderstanding and conflict, resulting in a lower likelihood that different perspectives about the problem will be integrated.

Idea Generation. A robust body of research exists on the cognitive process of idea generation, or brainstorming in teams (Paulus \& Brown, 2003). The majority of the research on brainstorming focuses on the number of ideas generated and not necessarily the creativity of those ideas (ReiterPalmon et al., 2011). Further, early research indicates that nominal groups may be just as effective as teams in generating ideas when the focus is number of ideas generated (Mullen et al., 1991). However, research on the effects of brainstorming on the quality or originality of ideas is more limited and not as conclusive (Barki \& Pinsonneault, 2001; Diehl \& Stroebe, 1987; Grawitch et al., 2003; Mullen et al., 1991; Sutton \& Hargadon, 1996).

The early findings that brainstorming may not result in more creative ideas was surprising and has led researchers to investigate the reasons for the lack of improvement over individual-level or nominal group level idea generation. One concern with using teams for any task is that there is often a pattern of non-participation or production loss (Dennis \& Valacich, 1993). A number of reasons for production loss have emerged. First, it has been suggested that team members may suffer from evaluation apprehension and therefore be reluctant to share ideas with others (Collaros \& Anderson, 1969). Second, production blocking may occur (Lamm \& Trommsdorf, 1973). That is, some group members, in an attempt to be polite, may wait and take turns to express ideas. This may result in a two-fold loss of ideas; the person waiting may lose track of the idea, and because the idea was withheld it will not spark any other ideas from other team members (Nijstad \& Strobe, 2006).

After identifying potential reasons for production loss, research shifted to identifying and evaluating ways in which production loss can be overcome or mitigated. An important method has emerged in the use of technology during brainstorming. Electronic Brainstorming (EBS) tools have been available since the early 1980s and have improved over the years with progress made in computer-mediated communication and technology. EBS aims to avoid production loss by allowing team members to generate ideas simultaneously. A meta-analysis on EBS has found that overall EBS results in the generation of more ideas compared to traditional brainstorming and nominal groups, and that this effect increases as the size of the team increases (Dennis \& Willaims, 2005; DeRosa et al., 2007). Many EBS systems also allow for user anonymity which can help overcome the issue of evaluation apprehension (Sosik et al., 1998). While the majority of the work on EBS has not 
focused specifically on virtual teams, the work does have important implications for understanding the cognitive process of idea generation in teams, with some attention to idea evaluation and selection (Maaravi et al., 2020). Regarding the outcomes of EBS, however, the focus tended to be on the number of ideas rather than the creativity of those ideas (Maaravi et al., 2020). Team creative processes that are used to evaluate and choose ideas that are worth implementing can help identify ideas that are truly novel and useful.

Idea Evaluation and Selection. Idea evaluation and selection refers to the process of evaluating ideas with respect to specific standards or goals and the subsequent selection of an idea to implement. Idea evaluation and selection is viewed as critical for the implementation of creative ideas and creative problem solving, and therefore has received increased attention from creativity researchers in the last decade (Rietzschel \& Ritter, 2018). In part, the emphasis on this concept is due to the need for organizations to select the most effective idea to implement (Sharma, 1999). The quality and originality of the final idea selected for implementation will depend on the quality of the evaluation and selection process. While some research suggests that individuals and teams can correctly evaluate ideas for creativity (e.g., Basadur et al., 2000; Benedeck et al., 2016; Blair \& Mumford, 2007; Runco, \& Vega, 2000), other work suggests that individuals and teams cannot accurately identify creative ideas among the many presented (Blair \& Mumford, 2007; Rietzschel et al., 2010; Reiter-Palmon et al., 2018). Mumford and colleagues (2002) suggested that the process of idea evaluation and selection is deeply contextualized. That is, the situation and circumstance of evaluation plays a role in its successes. The virtual context likely bears some influence on the evaluation and selection of creative ideas; however, direct research on the topic is limited. Still, studies on situational influences on evaluation and selection reveal how the process could unfold in virtual teams.

It is important to note that accurate idea evaluation is important. However, accuracy alone does not ensure that the ideas selected for implementation will be the most creative. Blair \& Mumford (2007) found that participants tended to reject highly original or risky ideas and were more likely to select ideas that were consistent with social norms, easy to understand, and likely to quickly lead to desirable outcomes, unless under high time pressure. Reiter-Palmon et al. (2018) has found that teams tended to be less likely to choose creative ideas and sometimes even preferred ideas that were lower on quality. Social cues seem to be particularly important for idea selection. Research indicates that when individuals are asked to select ideas and have access to the opinions of others, social cues play an important role in selecting which idea to implement (Fleury et al., 2020; Mueller et al. 2018). Finally, Harvey and Kou (2013) investigated the relationship between idea generation and idea evaluation in teams. While some teams focused first on idea generation followed by idea evaluations, some teams cycled through and alternated idea generation, followed by idea evaluation and repeated. The researchers suggested that when teams alternated between idea generation and idea evaluation, engaging in the process of idea evaluation supported the development of a shared framework for the problem at hand. The importance of a shared framework, or a shared 
mental model (SMM; Cannon-Bowers et al., 1993), has also been suggested by Mumford et al. (2001). In this study, a shared understanding of the problem also created a shared understanding of how to evaluate the solutions generated or standards, which in turn allowed the selection of the most creative solution. The limited work on team idea evaluation and selection has indicated that shared understanding, a social-cognitive emergent process, is important for effective idea evaluation and selection. SMMs are developed through communication, discussions, and previous shared experiences in the team (Mathieu et al., 2000; Zajac, et. al., 2014). However, direct research on the role of communication and information sharing on idea evaluation and selection is lacking. It has been suggested that teams, especially diverse teams, may perform well during idea evaluation as the diversity of perspectives ensures that multiple concerns and viewpoints are considered during the idea evaluation process. As such, more accurate evaluations may result (Reiter-Palmon et al., 2011).

\section{CREATIVITY IN VIRTUAL TEAMS}

Research focusing on creativity in virtual teams is limited (Chamakoitis et al., 2013). In fact, much of the discussion regarding creativity in virtual teams tends to be theoretical, with limited empirical evaluation of the factors that may facilitate or inhibit creativity. Theoretical discussions regarding creativity in virtual teams emphasize the difficult nature of communication in virtual teams, as certain modalities can inhibit the trust and psychological safety needed for effective creative collaboration (Nemiro, 2002; Ocker, 2005). Indeed, one study focused on end-user community innovations found that the quality of the interactions between community members was critical for innovation and that trust was an important antecedent of interaction quality (Frey \& Luthje, 2011). Other related work focuses on the role of EBS in idea generation and to some extent on idea evaluation. While the research provides some important implications for virtual teams, in many cases it is unclear whether teams are actually virtual or co-located. In fact, many studies have used existing and colocated teams, where the EBS was only used for the purpose of the idea generation, and the teams did not use other virtual communication technologies in their day-to-day work (DeRosa et al., 2007). As such, it is not clear to what extent we can extrapolate from EBS research to virtual teams.

The only study that has directly investigated communication modality in virtual teams and creativity was conducted by Han et al. (2011). The study included teams of 4 students focusing on a task called the Computerized Post Office (Han et al., 2011). Participants were asked to develop recommendations and a final report for the Computerized Post Office working together over a period of 2 weeks. The reports were then evaluated for creativity of the recommendations. The results indicated that there were no significant differences between communication modalities across the different conditions. However, this study suffered from a number of limitations. First, the study had a small sample size (7-8 groups per condition) and therefore limited power. Importantly, the means on creativity ratings ranged from 3.5 to 5.1 on a 7-point scale, indicating the possibility of 
differences if power was sufficient. Second, the study did not evaluate differences based on specific cognitive processes or social processes that may contribute to team success or failure. Further, the modalities themselves presented a considerable limitation: synchronous media modalities were used for an initial meeting between teams, with follow-up meetings being asynchronous. Perhaps even more significant, the date of the study (2011) meant that technological difficulties were still persistent in a way that they are not today. Virtual communication technology has improved greatly, and its widespread use indicates most participants will have basic knowledge of, and ability to use, these technologies. Rising digital literacy among the workforce implies that virtual teams will likely be a key feature in future organizations. Further, in 2011 modalities were limited to text, audio, or video, and teams were not able to use additional aids that are available today, including sharing documents, screen sharing, or annotation overlays. Thus, there continues to be many opportunities for future inquiry that further test the ideas from Han et al. and others discussed.

\section{SOCIAL PROCESSES IN VIRTUAL TEAMS}

Although improved technology may have attenuated some constraints on virtual teams, teams may still encounter problems related to their social interaction in a virtual space. When examining the impact that working virtually has on team processes, we are met with some consistent challenges related to perceived identification with the team. Specifically, when teammates are faced with using a virtual modality that is not high in media richness, the decrease in social presence often leads to disconnection from one's teammates and a lack of belongingness (Curseu et al., 2008). These perceptions can then lead to an array of problematic outcomes, as evidenced by meta-analyses on virtual teams including increased conflict, decreased communication, knowledge sharing, and openness (Mesmer-Magnus, et. al., 2011; De Guinea et al., 2012). For these reasons, among others, it is often suggested that virtual teammates must establish rapport with one another before formally beginning taskwork (Saunders, 2000). This can be done in a few different ways including meeting solely for the purpose of introductions, discussing the best approach to the assigned task, or generating a team charter that outlines roles and responsibilities. However, the underlying principle remains the same: it is imperative to provide distributed, virtual teammates the opportunity to build a psychologically safe social environment where information can flow freely without the fear of retaliation. Indeed, research has shown that virtual teams which engage in these initial processes exhibit higher levels of trust and effectiveness (Suchan \& Hayzak, 2001).

Moreover, research on virtual team processes shows that, due to the hurdles of geographic distance and decreased face-to-face interaction, it is easier to develop problems with trust (DeJong \& Elfring, 2010). Indeed, a meta-analysis on trust in virtual teams by Breuer, Huffmeier, and Hertel (2016) showed that trust had a stronger impact on performance in virtual ( $\alpha=.33$ ) versus face-toface teams $(a=.22)$ and that levels of trust significantly impacted a team's information processes via knowledge sharing, risk-taking behaviors, and team learning. This same study found that when 
virtual teams kept documentation of team processes and responsibilities, maintaining high levels of trust was more important for team effectiveness. This is especially important to consider when a team is engaged in innovative processes seeing as idea generation and evaluation are heavily grounded in the public sharing of ideas via tools such as document sharing (De Leede et al., 2008). Ultimately, there are numerous outcomes linked to deficits in virtual team trust, including decreased coordination (Kanawattanachai \& Yoo, 2007), cohesion (DeRosa et. al., 2014), and comfort using the virtual medium (Gaan, 2012).

Due to the often ad hoc nature of virtual teams, especially those with creative outcomes, the most challenging period of establishing trust is often at the beginning of the team's life cycle (Crisp \& Jarvenpaa, 2013). As such, research on virtual teams has highlighted the idea of promoting swift trust in temporary virtual teams. Swift trust, as a process, involves deemphasizing interpersonal relationships at the beginning of the team's tenure and, instead, having teammates establish high levels of trust with one another via actions and involvement on the team's task (Jarvenpaa \& Leidner, 1999). In this sense, the action and involvement of teammates are seen as a proxy for rapport building and indicate that a team will be able to complete their task, be vulnerable to one another, and overcome any ambiguity during the process. However, the main flaw in swift trust is that, as a team has more time and experience working together, they are more likely to find that a person's behavior or actions call trust into question. Therefore, as a virtual team's tenure progresses, swift trust becomes more fragile and additional social and cognitive processes need to be put into place as reinforcement (Hambley, et al., 2007). For instance, in the latter stages of tenure, if a virtual team engages in teammate monitoring and the clear identification of members' changing roles, task-related norming can serve as a support to maintain high levels of trust (Crisp \& Jarvenpaa, 2013).

Not surprisingly, as cognitive processes similar to learning (e.g., information exchange, team communication) take place, constructs related to open, free, and positive exchange of information within the team, such as psychological safety and reflexivity, have been found consistently to be related to team creativity and innovation (Carmeli \& Spreitzer, 2009; Edmondson, 2004; ReiterPalmon et al., 2018; West \& Anderson, 1996). Similarly, information exchange and communication have been found to be related to increased creativity and innovation. However, the nature of that communication is critical. Considerable research has found that teams who engage in positive patterns of communication, collaboration, support are more creative (Drach-Zehavy \& Somech, 2001; Hulsherger et al., 2009; Lovelace et al., 2001). On the other hand, relationship conflict and excessive task conflict are related to lowered creativity (De Dreu, 2006).

While a fair amount of research exists on the relationship between social processes in teams and creativity, much of that research is limited to more static, cross-sectional data. Research evaluating teams longitudinally finds that the effect of social processes and teamwork variables on creativity can vary over time (Hoegl et al., 2004). In addition, research has not fully integrated the two types of processes - social and cognitive - that are important for team creativity, nor have they considered the virtual environment where much of creativity and innovation must occur now. 
In addition to work on cognitive and social processes by creativity research, albeit not among virtual teams, meetings researchers continue to explore and investigate the various communication behaviors that augment or detract from successful meetings. For example, Lehmann-Willenbrock and colleagues (2013) found that procedural communication behaviors (e.g. "thanks for that idea, but let's focus on the key purpose of the meeting now") are essential for accomplishing overarching meeting purposes and result in more satisfying and effective meeting experiences. In a follow-up study, Lehmann-Willenbrock and Allen (2014) found that humor behaviors in teams enable objective team performance, but only when that humor was affiliative in nature, rather than put-down humor. These and other real-time behavioral processes need investigation within the context of teams attempting to engage in creative processes, as these processes are likely to enable or constrain creativity (Lehmann-Willenbrock \& Allen, 2018). Preliminary indications are that these behaviors are also present in virtual team meetings (Reed \& Allen, 2021). In fact, current estimates suggest that between $70 \%$ and $80 \%$ of pre-COVID-19 meeting best practices still apply in fully virtual contexts (Reed \& Allen, 2021).

\section{CREATIVITY IN VIRTUAL TEAMS - AGENDA FOR FUTURE RESEARCH}

Given the paucity of research on virtual team creativity and the increase in the number of geographically dispersed and virtual teams, a number of important questions emerge. These questions include issues related to both modality and social/cognitive processes and the interaction between these domains. Table 1 includes a list of research questions, and we have expanded on several of them in the text below.

One important issue that needs to be addressed is whether communication modality has differential effects based on the specific process of the creative problem-solving effort. Research evaluating these processes at the individual and team level suggests that the antecedents to effective application of these processes vary across levels (Reiter-Palmon, 2018; Reiter-Palmon et al., 2008). McGrath and Hollingshead (1993) suggested that more rich media was not always the most beneficial. In fact, recent studies suggest that the richer medium of video-conferencing may lead to higher levels of overall meeting fatigue (Fosslien \& Duffy, 2020). Rather, media richness needs to fit the purpose of the task and the meeting. For example, they argued that when the purpose of the team meeting is to generate many ideas, text-based media were a better fit than video-based media. That is, less rich media were a better fit because more rich media may cause distraction. In fact, the work on EBS supports this contention (e.g. Gallupe et al., 1992). In contrast, McGrath and Hollingshead (1993) further suggested that when conflict is high, more rich media are most appropriate because they allow for better negotiation and lower likelihood of misunderstanding. Given that conflict can arise at various points of the creative process, but especially during the problem construction and idea evaluation processes, video capabilities may be more suitable. 
Table 1. Questions to Guide Future Research on Creativity in Virtual Teams

\section{Questions related to communication modality}

- Does communication modality have differential effects based on the specific process of the creative problem-solving effort (problem identification and construction, idea generation, idea evaluation and selection)?

- Does using additional features of virtual meeting technology influence the creativity of the output?

- Does the use of additional features have differential effects based on the specific process of the creative problem-solving effort (problem identification and construction, idea generation, idea evaluation and selection)?

\section{Questions related to social processes in virtual teams}

- How do social processes in virtual teams influence the creativity of the output?

- Do social processes have differential effects based on the specific process of the creative problem-solving effort (problem identification and construction, idea generation, idea evaluation and selection)?

- How do social processes influence creativity when teams are hybrid (i.e., when some members are face to face and some are virtual)?

\section{Questions related to the interaction of communicational modality and social processes}

- How do communication modalities and the use of additional features influence the development of social processes in creative virtual teams?

- How do the inter-relationships between cognitive processes and social processes unfold over time and are they dependent on communication modality?

- How do social processes, cognitive processes, and communication modalities interact to influence the outcome of the creative problem-solving effort?

- How do social processes influence creativity when teams use multi-modal communication (i.e., when some team members use voice while others use video)?

However, no research to date has investigated whether there are differences in process effectiveness based on specific communication modalities. One way in which this gap can be addressed would be to focus on specific creative processes and evaluate the effectiveness of the process under different modes of communication directly. For example, teams can be asked to actively engage in problem construction using the three main modalities (i.e., text-based, teleconferencing, video conferencing). The quality and originality of the resulting problem restatements can then be evaluated. Similarly, we can assess whether idea evaluation effectiveness differs across modalities by focusing only on the accuracy of a team's idea evaluations.

Given the variety of different modalities, there is also the possibility of multiple modalities being used at the same time, or over time. For example, the notion of hybrid teams, where some team members meet face-to-face, while others join remotely has already been explored (Fiol \& O'Connor, 2005). Fiol and O'Connor suggested that hybrid teams face unique challenges compared to face-to-face or pure virtual teams, especially those related to social processes. For example, the networks of communication vary dramatically based on the nature of the hybrid meeting, creating more or less opportunity for social interaction within the meeting context (Reed \& Allen, 2021). However, research on hybrid teams is limited, and even more in relation to creativity and innovation. The use of hybrid teams will likely increase as some team members will work in the office part of the week, and some will work at home. Understanding how team interactions and social processes 
unfold for hybrid teams and how those social processes may influence different creative cognitive processes is important. For example, some tasks such as ideation may be more suited for a hybrid format, whereas other tasks such idea evaluation may be better conducted when all team members can meet face to face.

In addition, team members likely use multiple modalities at the same time. At times team members may choose to use audio only, potentially due to broadband issues, being on the road, or a distracting background, whereas at other times they may choose to use video. Moreover, different team members may join the virtual space using different modalities for the same meeting. You can find a number of articles in the popular press advocating for turning off cameras as a way to reduce anxiety, stress, and zoom fatigue, whereas other articles indicate that meeting participants or students who have turned off the camera may be disengaged (c.f., Marks, 2020; Shearn, 2021; Wasche, 2020). Research should determine whether the use of different modalities in the same meeting influences creative outcomes and whether there are differential effects based the cognitive process. Specifically, both within lab and in the field, studies are needed that fully describe the modalities being used for a given meeting, and the outcomes thereof, so as to draw comparison across modalities. It is likely that although there are many different potential modality combinations (e.g. two on audio, three on video, two face-to-face, with some interlocking mechanism), some patterns of results may provide indications of which modality combinations work and which do not.

\section{CONCLUSION}

On the outset, organizations and teams now need to be able to collaborate more effectively, and even generate creative solutions, outside what was normal operating procedures (i.e. face-to-face). The rapid improvement of technology over the past few years and its proliferation over a global pandemic has exposed possibilities of working virtually to more and more organizations. The switch to virtual contexts introduces both opportunities (e.g., meet anywhere, anytime, with just about anyone) and challenges (e.g. multiple modality contributions converging, simultaneously competing for human attention) in relation to creative processes, meeting processes, and virtual team success or failure. Our postulations and ideas for a future agenda to manage these opportunities come at a time when it is almost too late. Our hope is that many pick up the challenge to solve the modern working world challenges, some of which we noted herein.

\section{References}

Abdulla, A.M., Paek, S.H., Cramond, B., \& Runco, M.A. (2020). Problem finding and creativity: A meta-analytic review. Psychology of Aesthetics, Creativity, and the Arts, 14(1), 3-14. https://doi.org/10.1037/aca0000194

Allison, B.B., Shuffler, M.L., \& Wallace, A.M. (2015). The successful facilitation of virtual team meetings. In The Cambridge handbook of meeting science (pp. 680-706). New York, NY: Cambridge University Press. 
Anderson, N., De Dreu, C.K.W., \& Nijstad, B.A. (2004). The routinization of innovation research: A constructively critical review of the state-of-the-science. Journal of Organizational Behavior, 25(2), 147-173. https://doi.org/10.1002/job.236

Anderson, N., Potočnik, K., \& Zhou, J. (2014). Innovation and creativity in organizations: A state-of-the-science review, prospective commentary, and guiding framework. Journal of Management, 40(5), 12971333. https://doi.org/10.1177/0149206314527128

Andriessen J.H.E. (2003) System match theories. In: J.H. Andriessen (Ed.), Working with Groupware: Understanding and Evaluating Collaborative Technology. Springer, London. https://doi.org/10.1007/978-14471-0067-6_5

Arreola, N.J., \& Reiter-Palmon, R. (2016). The effect of problem construction creativity on solution creativity across multiple everyday problems. Psychology of Aesthetics, Creativity, and the Arts, 10(3), 287-295. https://doi.org/10.1037/a0040389

Aritz,J.,Walker, R., \&Cardon,P.W.(2018).Media useinvirtualteams ofvarying levels of coordination. Businessand Professional Communication Quarterly, 81(2), 222-243. https://doi.org/10.1177\%2F2329490617723114

Barki, H., \& Pinsonneault, A. (2001). Small group brainstorming and idea quality: Is electronic brainstorming the most effective approach? Small Group Research, 32(2), 158-205. https://doi.org/10.1177/104649640 103200203

Basadur, M., Runco, M.A., \& Vega, L.A. (2000). Understanding how creative thinking skills, attitudes and behaviors work together: A causal process model. Journal of Creative Behavior, 34, 77-100. https://doi. org/10.1002/j.2162-6057.2000.tb01203.x

Benedek, M., Nordtvedt, N., Jauk, E., Koschmieder, C., Pretsch, J., Krammer, G., \& Neubauer, A.C. (2016). Assessment of creativity evaluation skills: A psychometric investigation prospective teachers. Thinking Skills and Creativity, 21, 75-84. https://doi.org/10.1016/j.tsc.2016.05.007

Blair, C.S., \& Mumford, M.D. (2007). Errors in idea evaluation: Preference for the unoriginal? The Journal of Creative Behavior, 41(3), 197-222. https://doi.org/10.1002/j.2162-6057.2007.tb01288.x

Bos, N., Gergle, D., Olson, J.S., \& Olson, G.M. (2001). Being there versus seeing there: Trust via video. In: M. M. Tremaine (Ed.), Extended Abstracts on Human Factors in Computing Systems (pp. 291-292). https://doi. org/10.1145/634067.634240

Bowers, C., Smith, P.A., Cannon-Bowers, J., \& Nicholson, D. (2008). Using virtual worlds to assist distributed teams. In: P. Zemliansky \& K.S. Amant (Eds.), The Handbook of Research on Virtual Workplaces and the New Nature of Business Practices (pp. 408-423). Idea Group Inc. http://dx.doi.org/10.4018/978-1-59904893-2

Breuer, C., Hüffmeier, J., \& Hertel, G. (2016). Does trust matter more in virtual teams? A meta-analysis of trust and team effectiveness considering virtuality and documentation as moderators. Journal of Applied Psychology, 101(8), 1151-1177. https://doi.org/10.1037/apl0000113

Caniëls, M.C., \& Rietzschel, E.F. (2015). Organizing creativity: Creativity and innovation under constraints. Creativity and Innovation Management, 24(2), 184-196. https://doi.org/10.1111/caim.12123

Cannon-Bowers, J.A., Salas, E., \& Converse, S. (1993). Shared mental models in expert team decision making. In N.J. Castellan, Jr. (Ed.), Individual and group decision making: Current issues (pp. 221-246). Lawrence Erlbaum Associates.

Carmeli, A., \& Spreitzer, G.M. (2009). Trust, connectivity, and thriving: Implications for innovative behaviors at work. The Journal of Creative Behavior, 43(3), 169-191. https://doi.org/10.1002/j.2162-6057.2009. tb01313.x

Cascio, W.F. (2000). Managing a virtual workplace. Academy of Management Perspectives, 14(3), 81-90. https://doi.org/10.5465/ame.2000.4468068

Chamakiotis, P., Dekoninck, E.A., \& Panteli, N. (2013). Factors influencing creativity in virtual design teams: An interplay between technology, teams and individuals. Creativity and Innovation Management, 22(3), 265-279. https://doi.org/10.1111/caim.12039

Collaros, P.A., \& Anderson, L.R. (1969). Effect of perceived expertness upon creativity of members of brainstorming groups. Journal of Applied Psychology, 53(2, Pt.1), 159-163. https://doi.org/10.1037/h0027034 
Cooke, N.J. (2015). Team Cognition as Interaction. Current Directions in Psychological Science, 24(6), 415-419. https://doi.org/10.1177/0963721415602474

Crisp, C.B., \& Jarvenpaa, S.L. (2013). Swift trust in global virtual teams: Trusting beliefs and normative actions. Journal of Personnel Psychology, 12(1), 45-56. https://psycnet.apa.org/doi/10.1027/1866-5888/ a000075

Cronin, M.A., \& Weingart, L.R. (2007). Representational gaps, information processing, and conflict in functionally diverse teams. The Academy of Management Review, 32(3), 761-773. https://doi. org/10.2307/20159333

CultureWizard by RW3. (2016). Trends in Global Virtual Teams: Virtual Teams Survey Report. https://www.rw3.com/2016-trends-in-virtual-teams-report?submissionGuid=06a8ef96-e6e6-4c77-a010-6b5e71b33d24

Curşeu, P.L., Schalk, R., \& Wessel, I. (2008). How do virtual teams process information? A literature review and implications for management. Journal of Managerial Psychology, 23(6). 628-652. https://doi.org/10.110 8/02683940810894729

Daft, R.L., \& Lengel, R.H. (1986). Organizational information requirements, media richness and structural design. Management Science, 32(5), 554-571. https://doi.org/10.1287/mnsc.32.5.554

De Dreu, C.K.W. (2006). When too little or too much hurts: Evidence for a curvilinear relationship between task conflict and innovation in teams. Journal of Management, 32(1), 83-107. https://doi.org/10.1177/01 49206305277795

De Dreu, C.K.W., Nijstad, B.A., Bechtoldt, M.N., \& Baas, M. (2011). Group creativity and innovation: A motivated information processing perspective. Psychology of Aesthetics, Creativity, and the Arts, 5(1), 81-89. https://doi.org/10.1037/a0017986

De Guinea, A. O., Webster, J., \& Staples, D. S. (2012). A meta-analysis of the consequences of virtualness on team functioning. Information \& Management, 49(6), 301-308. https://doi.org/10.1016/j.im.2012.08.003

De Jong, B.A., \& Elfring, T. (2010). How does trust affect the performance of ongoing teams? The mediating role of reflexivity, monitoring, and effort. Academy of Management Journal, 53(3), 535-549.

De Leede, J., Kraan, K.O., Den Hengst, M., \& van Hooff, M.L. (2008). Conditions for innovation behaviour of virtual team members: a'high-road'for internationally dispersed virtual teams. Journal of eWorking, 2(1).

Dennis, A.R., \& Kinney, S.T. (1998). Testing media richness theory in the new media: The effects of cues, feedback, and task equivocality. Information Systems Research, 9(3), 256-274. https://doi.org/10.1287/ isre.9.3.256

Dennis, A.R., \& Valacich, J.S. (1993). Computer brainstorms: More heads are better than one. Journal of Applied Psychology, 78(4), 531-537. https://doi.org/10.1037/0021-9010.78.4.531

Dennis, A.R., \& Williams, M.L. (2003). Electronic brainstorming: Theory, research, and future directions. In P.B. Paulus \& B.A. Nijstad (Eds.), Group creativity: Innovation through collaboration (pp. 160-178). Oxford University Press. https://doi.org/10.1093/acprof:oso/9780195147308.003.0008

Dess, G.G., \& Picken, J.C. (2000). Changing roles: Leadership in the $21^{\text {st }}$ century. Organizational dynamics, 28(3), 18-34. https://doi.org/10.1016/S0090-2616(00)88447-8

DeRosa, D.M., Hantula, D.A., Kock, N., \& D'Arcy, J. (2004). Trust and leadership in virtual teamwork: A media naturalness perspective. Human Resource Management: Published in Cooperation with the School of Business Administration, The University of Michigan and in alliance with the Society of Human Resources Management, 43(2-3), 219-232.

DeRosa, D.M., Smith, C.L., \& Hantula, D.A. (2007). The medium matters: Mining the long-promised merit of group interaction in creative idea generation tasks in a meta-analysis of the electronic group brainstorming literature. Computers in Human Behavior, 23(3), 1549-1581. https://doi.org/10.1016/ j.chb.2005.07.003

Diehl, M., \&Stroebe, W. (1991). Productivity loss in idea-generating groups: Tracking down the blocking effect. Journal of Personality and Social Psychology, 61(3), 392-403. https://doi.org/10.1037/0022-3514.61.3.392 
Drach-Zahavy, A., \& Somech, A. (2001). Understanding team innovation: The role of team processes and structures. Group Dynamics: Theory, Research, and Practice, 5(2), 111-123. https://doi.org/10.1037/10892699.5.2.111

Driskell, J.E., Radtke, P.H., \& Salas, E. (2003). Virtual teams: Effects of technological mediation on team performance. Group Dynamics: Theory, Research, and Practice, 7(4), 297-323. https://psycnet.apa.org/ doi/10.1037/1089-2699.7.4.297

Edmondson, A. (2004). Psychological safety, trust, and learning in organizations: A group-level lens. In R.M. Kramer, \& K.S. Cook (Eds.), Trust and distrust in organizations: Dilemmas and approaches (pp. 239-272). Russell Sage Foundation.

Fiol, C.M., \& O'Connor, E.J. (2005). Identification in face-to-face, hybrid, and pure virtual teams: Untangling the contradictions. Organization Science, 16, 19-32. https://doi.org/10.1287/orsc.1040.0101

Fleury, S., Agnes, A., Cados, L., Denis-Lutard, Q., Duchêne, C., Rigaud, N., \& Richir, S. (2020). Effects of social influence on idea selection in creativity workshops. Thinking Skills and Creativity, 37, 100691. https://doi. org/10.1016/j.tsc.2020.100691

Fosslien, L., \& Duffy, M.W. (2020). How to combat zoom fatigue. Harvard Business Review, 29.

Frey, K., Lüthje, C., \& Haag, S. (2011). Whom should firms attract to open innovation platforms? The role of knowledge diversity and motivation. Long Range Planning, 44(5-6), 397-420. https://doi.org/10.1016/ j.Irp.2011.09.006

Gaan, N. (2012). Collaborative tools and virtual team effectiveness: An inductively derived approach in India's software sector. Decision (0304-0941), 39(1).

Gallupe, R.B., Dennis, A.R., Cooper, W.H., Valacich, J.S., Bastianutti, L.M., \& Nunamaker Jr, J.F. (1992). Electronic brainstorming and group size. Academy of Management Journal, 35(2), 350-369. https://doi. org/10.5465/256377

Gish, L., \& Clausen, C. (2013). The framing of product ideas in the making: a case study of the development of an energy saving pump. Technology Analysis \& Strategic Management, 25(9), 1085-1101. https://doi. org/10.1080/09537325.2013.832746

Goh, K.T., Goodman, P.S., \& Weingart, L.R. (2013). Team innovation processes: An examination of activity cycles in creative project teams. Small Group Research, 44(2), 159-194. https://doi.org/10.1177/1046496 413483326

Grawitch, M.J., Munz, D.C., \& Kramer, T.J. (2003). Effects of member mood states on creative performance in temporary workgroups. Group Dynamics: Theory, Research, and Practice, 7(1), 41-54. https://doi. org/10.1037/1089-2699.7.1.41

Hambley, L.A., O'Neill, T.A., \& Kline, T.J. (2007). Virtual team leadership: The effects of leadership style and communication medium on team interaction styles and outcomes. Organizational behavior and human decision processes, 103(1), 1-20.

Han, H.J., Hiltz, S.R., Fjermestad, J., \& Wang, Y.Q. (2011). Does medium matter? A comparison of initial meeting modes for virtual teams. IEEE Transactions on Professional Communication, 54, 376-391. https://doi. org/10.1109/TPC.2011.2175759

Harvey, S. (2014). Creative synthesis: Exploring the process of extraordinary group creativity. Academy of Management Review, 39(3), 324-343. https://doi.org/10.5465/amr.2012.0224

Harvey, S., \& Kou, C.Y. (2013). Collective engagement in creative tasks: The role of evaluation in the creative process in groups. Administrative Science Quarterly, 58, 346-386. https://doi.org/10.1177/00018392134 98591

Haught-Tromp, C. (2016). Creativity and constraint: Friends, not foes. In J.C. Kaufman \& J. Baer (Eds.), Current perspectives in social and behavioral sciences. Creativity and reason in cognitive development (p. 211-225). Cambridge University Press. https://doi.org/10.1017/CBO9781139941969.011

Hennessey, B.A., \& Amabile, T.M. (2010). Creativity. Annual Review of Psychology, 61, 569-598. https://doi. org/10.1146/annurev.psych.093008.100416 
Hoegl, M., Weinkauf, K., \& Gemuenden, H.G. (2004). Interteam Coordination, Project Commitment, and Teamwork in Multiteam R\&D Projects: A Longitudinal Study. Organization Science, 15(1), 38-55. https:// doi.org/10.1287/orsc.1030.0053

Hogg, M.A., \& Reid, S.A. (2006). Social identity, self-categorization, and the communication of group norms. Communication Theory, 16(1), 7-30. https://doi.org/10.1111/j.1468-2885.2006.00003.x

Hollingshead, A.B., McGrath, J.E., \& O'Connor, K.M. (1993). Group task performance and communication technology: A longitudinal study of computer-mediated versus face-to-face work groups. Small Group Research, 24(3), 307-333. https://doi.org/10.1177\%2F1046496493243003

Hülsheger, U.R., Anderson, N., \& Salgado, J.F. (2009). Team-level predictors of innovation at work: A comprehensive meta-analysis spanning three decades of research. Journal of Applied Psychology, 94(5), 1128-1145. https://doi.org/10.1037/a0015978

Ishii, K., Lyons, M.M., \& Carr, S.A. (2019). Revisiting media richness theory for today and future. Human Behavior and Emerging Technologies, 1(2), 124-131. https://doi.org/10.1002/hbe2.138

Jarvenpaa, S.L., \& Keating, E. (2021). When do good communication models fail in global virtual teams? Organizational Dynamics, 50(1), No. 100843. https://doi.org/10.1016/j.orgdyn.2021.100843

Jarvenpaa, S.L., \& Leidner, D.E. (1999). Communication and trust in global virtual teams. Organization Science, 10(6), 791-815. https://doi.org/10.1287/orsc.10.6.791

Kanawattanachai, P., \& Yoo, Y. (2007). The impact of knowledge coordination on virtual team performance over time. MIS quarterly, 783-808. https://doi.org/10.2307/25148820

Kanawattanachai, P., \& Yoo, Y. (2002). Dynamic nature of trust in virtual teams. The Journal of Strategic Information Systems, 11(3). https://doi.org/10.1016/S0963-8687(02)00019-7

Kirkman, B.L., \& Mathieu, J.E. (2005). The dimensions and antecedents of team virtuality. Journal of Management, 31(5), 700-718. https://doi.org/10.1177/0149206305279113

Kozlowski, S.W., \& Bell, B.S. (2008). Team learning, development, and adaptation. In: V.I. Sessa \& M.L. London (Eds.), Work Group Learning: Understanding, Improving \& Assessing how Groups Learn in Organizations (pp. 15-44). Psychology Press.

Kwak, H. (2012). Self-disclosure in online media: An active audience perspective. International Journal of Advertising, 31(3), 485-510. https://doi.org/10.2501/IJA-31-3-485-510

Lamm, H., \& Trommsdorff, G. (1973). Group versus individual performance on tasks requiring ideational proficiency (brainstorming): A review. European Journal of Social Psychology, 3(4), 361-388. https://doi. org/10.1002/ejsp.2420030402

Lehmann-Willenbrock, N., \& Allen, J.A. (2018). Modeling temporal interaction dynamics in organizational settings. Journal of Business and Psychology, 33(3), 325-344. https://doi.org/10.1007/s10869-017-9506-9

Lehmann-Willenbrock, N., \& Allen, J.A. (2014). How fun are your meetings? Investigating the relationship between humor patterns in team interactions and team performance. Journal of Applied Psychology, 99(6), 1278-1287. https://doi.org/10.1037/a0038083

Lehmann-Willenbrock, N., Allen, J.A., \& Kauffeld, S. (2013). A sequential analysis of procedural meeting communication: How teams facilitate their meetings. Journal of Applied Communication Research, 41(4), 365-388. https://doi.org/10.1080/00909882.2013.844847

Leonardi, P.M. (2011). Innovation blindness: Culture, frames, and cross-boundary problem construction in the development of new technology concepts. Organization Science, 22(2), 347-369. https://doi. org/10.1287/orsc.1100.0529

Lovelace, K., Shapiro, D.L., \& Weingart, L.R. (2001). Maximizing cross-functional new product teams' innovativeness and constraint adherence: A conflict communications perspective. Academy of Management Journal, 44(4), 779-793. https://doi.org/10.2307/3069415

Maaravi, Y., Heller, B., Shoham, Y., Mohar, S., \& Deutsch, B. (2020). Ideation in the digital age: literature review and integrative model for electronic brainstorming. Review of Managerial Science, 1-34. https://doi. org/10.1007/s11846-020-00400-5 
Ma, H.H. (2009). The effect size of variables associated with creativity: A meta-analysis. Creativity Research Journal, 21, 30-42. https://doi.org/10.1080/10400410802633400

Marks, G. (2020). On CRM: should you, or should you not turn on your camera for that Zoom meeting? Forbes, May 1. https://www.forbes.com/sites/quickerbettertech/2020/05/01/on-crm-should-you-orshould-you-not-turn-on-your-camera-for-that-zoom-meeting/?sh=2595ba88bb06

Mathieu, J.E., Heffner, T.S., Goodwin, G.F., Salas, E., \& Cannon-Bowers, J.A. (2000). The influence of shared mental models on team process and performance. Journal of applied psychology, 85(2), 273-283. https://doi.org/10.1037/0021-9010.85.2.273

Marlow, S.L., Lacerenza, C.N., \& Salas, E. (2017). Communication in virtual teams: A conceptual framework and research agenda. Human Resource Management Review, 27(4), 575-589. https://doi.org/10.1016/ j.hrmr.2016.12.005

McGrath, J.E., \& Hollingshead, A.B. (1993). Putting the group back in group support systems: Some theoretical issues about dynamic processes in groups with technological enhancements. In L.M. Jessup \& J.S. Valacich (Eds.), Group support systems: New perspectives (pp. 78-96). New York: Macmillan.

Mckinsey (2021). The future of work after COVID-19. https://www.mckinsey.com/featured-insights/future-ofwork/the-future-of-work-after-covid-19\#

Medeiros, K.E., Watts, L.L., Mulhearn, T.J., Steele, L.M., Mumford, M.D., \& Connelly, S. (2017). What is working, what is not, and what we need to know: A meta-analytic review of business ethics instruction. Journal of Academic Ethics, 15(3), 245-275. https://doi.org/10.1007/s10805-017-9281-2

Mesmer-Magnus, J., \& DeChurch, L. (2009). Information sharing and team performance: A meta-analysis. Journal of Applied Psychology, 94, 535-546. https://doi.org/10.1109/emr.2012.6172774

Mesmer-Magnus, J.R., DeChurch, L.A., Jimenez-Rodriguez, M., Wildman, J., \& Shuffler, M. (2011). A meta-analytic investigation of virtuality and information sharing in teams. Organizational Behavior and Human Decision Processes, 115(2), 214-225. https://doi.org/10.1016/j.obhdp.2011.03.002

Microsoft (2020). Microsoft Teams at 3: Everything you need to connect with your teammates and be more productive. https://www.microsoft.com/enus/microsoft-365/blog/2020/03/19/microsoft-teams-3-everything-you-need-connectteammates-be-more-productive/

Mueller, J., Melwani, S., Loewenstein, J., \& Deal, J.J. (2018). Reframing the Decision-Makers' Dilemma: Towards a Social Context Model of Creative Idea Recognition. Academy of Management Journal, 61, 94110. https://doi.org/10.5465/amj.2013.0887

Mullen, B., Johnson, C, \& Salas, E. (1991). Productivity loss in brainstorming groups: A meta-analytic integration. Basic and Applied Social Psychology, 12, 3-23. https://doi.org/10.1108/eb022856

Mumford, M.D., Feldman, J.M., Hein, M.B., \& Nagao, D.J. (2001). Tradeoffs between ideas and structure: Individuals versus group performance in creative problem solving. The Journal of Creative Behavior, 35(1), 1-23. https://doi.org/10.1002/j.2162-6057.2001.tb01218.x

Mumford, M.D., \& Hunter, S.T. (2005). Innovation in organizations: A multi-level perspective on creativity. In: F. Dansereau \& F.J. Yammarino (Eds.), Multi-level Issues in Strategy and Methods (Research in Multi-Level Issues, Vol. 4) (pp. 9-73). Emerald Group Publishing Limited, Bingley. https://doi.org/10.1016/S14759144(05)04001-4

Mumford, M.D., Mobley, M.I., Reiter-Palmon, R., Uhlman, C.E., \& Doares, L.M. (1991). Process analytic models of creative capacities. Creativity Research Journal, 4(2), 91-122. https://doi.org/10.1080/1040041910953 4380

Mumford, M., Reiter-Palmon, R, \& Redmond, M. (1994). Problem construction and cognition: Applying problem representations in ill-defined domains. In M. Runco (Ed.), Problem finding, problem solving, and creativity (pp. 3-39). Ablex Publishing Corporation.

Mumford, M.D., Lonergan, D.C., \& Scott, G. (2002). Evaluating Creative Ideas: Processes, standards, and context. Inquiry: Critical Thinking Across the Disciplines, 22(1), 21-30. https://doi.org/10.5840/inquiryctnews 20022213

Nemiro, J.E. (2002). The creative process in virtual teams. Communication Research Journal, 14(1), 69-83. https://doi.org/10.1207/S15326934CRJ1401_6 
Nijstad, B.A., \& Stroebe, W. (2006). How the group affect the mind: a cognitive model of idea generation in groups. Personality and Social Psychology Bulletin, 10(3), 186-213. https://doi.org/10.1207/ s15327957pspr1003_1

Ocker, R.J. (2005). Influences on creativity in asynchronous virtual teams: A qualitative analysis of experimental teams. IEEE Transactions on Professional Communication, 48(1), 22-39. https://doi.org/10.1109/ TPC.2004.843294

O'Leary, M.B., \& Cummings, J.N. (2007). The spatial, temporal, and configurational characteristics of geographic dispersion in teams. MIS Quarterly, (31), 433-452. https://doi.org/10.2307/25148802

Paulus, P., \& Brown, V. (2003). Enhancing ideational creativity in groups: Lessons from research on brainstorming. In P.B. Paulus, B.A. Nijstad, \& A. Bernard (Eds.), Group creativity: Innovation through collaboration (pp. 110-136). Oxford University Press.

Reed, K.M. \& Allen, J.A. (2021). Suddenly Virtual: Making Remote Meetings Work. Hoboken, NJ: Wiley.

Reiter-Palmon, R. (2018). Creative cognition at the individual and team levels: What happens before and after idea generation. In: R.J. Sternberg \& J.C. Kaufman (Eds.), The Nature of Human Creativity (pp. 184202). Cambridge University Press.

Reiter-Palmon, R., \& Harms, M. (2017). Team creativity and innovation: Importance and directions. In: R.R. Palmon (Ed.), Team Creativity and Innovation (pp. 3-10). Oxford University Press.

Reiter-Palmon, R, Herman, A.E., \& Yammarino, F.J. (2008), Creativity and cognitive processes: Multi-level linkages between individual and team cognition. In: M.D. Mumford, S.T. Hunter, \& K.E. Bedell-Avers (Eds.), Multi-Level Issues in Creativity and Innovation: Research in Multi-Level Issues (Vol. 7, pp. 203-267). Emerald Group Publishing Limited.

Reiter-Palmon, R., Kennel, V.L., \& Allen, J.A. (2020). Teams in small organizations: Conceptual, methodological, and practical considerations. Frontiers in Psychology, 12, 1664-1078. https://doi.org/10.3389/fpsyg.2021.530291

Reiter-Palmon, R., Kennel, V., Allen, J., \& Jones, K.J. (2018). Good catch! using interdisciplinary teams and team reflexivity to improve patient safety. Group \& Organization Management, 43(3), 414-439. https:// doi.org/10.1177/1548051818781820

Reiter-Palmon, R., Kennel, V., de Vreede, T., \& de Vreede, G.J. (2018). Structuring team idea evaluation and selection of solution: Does it influence creativity? (pp. 209-224). In I. Lebuda \& V. Glavenou (Eds.), Palgrave Handbook of Social Creativity Research. Palgrave Press.

Reiter-Palmon, R., Mumford, M.D., O'Connor Boes, J., \& Runco, M.A. (1997). Problem construction and creativity: The role of ability, cue consistency, and active processing. Creativity Research Journal, 10, 9-23. https://doi.org/10.1207/s15326934crj1001_2

Reiter-Palmon, R., \& Murugavel, V. (2018). The effect of problem construction on team process and creativity. Frontiers in Psychology, 9, Article 2098. https://doi.org/10.3389/fpsyg.2018.02098

Reiter-Palmon, R., \& Robinson, E. (2009). Problem identification and construction: What do we know, what is the future? Psychology of Aesthetics, Creativity, and the Arts, 3, 43-47. https://doi.org/10.1037/a0014629

Reiter-Palmon, R., Wigert, B., \& Vreede, T.D. (2011). Team creativity and innovation: The effect of group composition, social processes, and cognition. In: M.D. Mumford (Ed.), Handbook of Organizational Creativity (pp. 295-326). Elsevier.

Rice, R.E. (1992). Task analyzability, use of new media, and effectiveness: A multi-site exploration of media richness. Organization Science, 3(4), 475-500. https://doi.org/10.1287/orsc.3.4.475

Rietzschel, E.F., \& Ritter, S.M. (2018). Moving from creativity to innovation. In R. Reiter-Palmon, V.L. Kennel, \& J.C. Kaufman (Eds.), Individual creativity in the workplace (p. 3-34). Elsevier Academic Press. https://doi. org/10.1016/B978-0-12-813238-8.00001-2

Rietzschel, E.F., Nijstad, B.A., \& Stroebe, W. (2010). The selection of creative ideas after individual idea generation: Choosing between creativity and impact. British Journal of Psychology, 101, 47-68. https://doi. org/10.1348/000712609X414204 
Robert Half (2021). 1 In 3 Remote Workers May Quit If Required To Return To The Office Full Time, Robert Half Survey Finds. https://rh-us.mediaroom.com/2021-04-06-1-In-3-Remote-Workers-May-Quit-If-RequiredTo-Return-To-The-Office-Full-Time-Robert-Half-Survey-Finds

Robey, D., Schwaig, K.S., \& Jin, L. (2003). Intertwining material and virtual work. Information and organization, 13(2), 111-129.

Rosso, B.D. (2014). Creativity and constraints: Exploring the role of constraints in the creative processes of research and development teams. Organization Studies, 35(4), 551-585. https://doi.org/10.1177/017084 0613517600

Runco, M.A., \& Vega, L. (1990). Evaluating the creativity of children's ideas. Journal of Social Behavior and Personality, 5(5), 439-452.

Saunders, C.S. (2000). Virtual teams: Piecing together the puzzle. In R.W. Zmud (Ed.), Framing the domain of IT management: Projecting the future... through the past (pp. 29-50). Pinnaflex.

Shalley, C.E., \& Gilson, L.L. (2004). What leaders need to know: A review of social and contextual factors that can foster or hinder creativity. The Leadership Quarterly, 15(1), 33-53. https://doi.org/10.1016/ j.leaqua.2003.12.004

Shalley, C.E., Zhou, J., \& Oldham, G.R. (2004). The effects of personal and contextual characteristics on creativity: Where should we go from here? Journal of Management, 30(6), 933-958. https://doi.org/10.1016/ j.jm.2004.06.007

Sharma, A. (1999). Central dilemmas of managing innovation in large firms. California Management Review, 41, 146-164. https://doi.org/10.2307/41166001

Shearn, A. (2021). It's time to start leaving our Zoom cameras off. Forge, February 18. https://forge.medium. com/its-time-to-start-leaving-our-zoom-cameras-off-c8a58bc66ae1

Sosik, J.J., Avolio, B.J., \& Kahai, S.S. (1997). Effects of leadership style and anonymity on group potency and effectiveness in a group decision support system environment. Journal of Applied Psychology, 82(1), 89-103. https://doi.org/10.1037/0021-9010.82.1.89

Staples, D.S., \& Webster, J. (2008). Exploring the effects of trust, task interdependence and virtualness on knowledge sharing in teams. Information Systems Journal, 18(6), 617-640. https://doi.org/10.1111/j.13652575.2007.00244.x

Sternberg, R.J. (1988). A three-facet model of creativity. In R.J. Sternberg (Ed.), The Nature of Creativity: Contemporary Psychological Perspectives (pp. 125-147). Cambridge University Press.

Suchan, J., \& Hayzak, G. (2001). The communication characteristics of virtual teams: A case study. IEEE transactions on Professional Communication, 44(3), 174-186. https://doi.org/10.1109/47.946463

Suh, K.S. (1999). Impact of communication medium on task performance and satisfaction: an examination of media-richness theory. Information \& Management, 35(5), 295-312. https://doi.org/10.1016/S03787206(98)00097-4

Sutton, R.I., \& Hargadon, A. (1996). Brainstorming groups in context: Effectiveness in a product design firm. Administrative Science Quarterly, 41(4), 685-718. https://doi.org/10.2307/2393872

Taggar, S. (2002). Individual creativity and group ability to utilize individual creative resources: A multilevel model. Academy of Management Journal, 45(2), 315-330. https://doi.org/10.5465/3069349

Taggar, S. (2019). The cognitive underpinnings of creativity in teams: Distal and proximal antecedents. In P.B. Paulus \& B.A. Nijstad (Eds.), The Oxford Handbook of Group Creativity and Innovation, 11-32. Oxford University Press.

Thomas, E. (2013). Supplier integration in new product development: Computer mediated communication, knowledge exchange and buyer performance. Industrial Marketing Management, 42(6), 890-899. https://doi.org/10.1016/j.indmarman.2013.05.018

Toader, A.F., Cantner, U., \& Kessler, T. (2019). The effect of team mental models divergence on creative performance during situational changes. Creativity Research Journal, 31(1), 40-51. https://doi.org/10.1080/ 10400419.2019.1577206 
Toader, A. F., \& Kessler, T. (2018). Team mental models, team goal orientations, and information elaboration, predicting team creative performance. Creativity Research Journal, 30(4), 380-390. https://doi.org/10.1 080/10400419.2018.1530912

Vernon, D., \& Hocking, I. (2016). Beyond belief: Structured techniques prove more effective than a placebo intervention in a problem construction task. Thinking Skills and Creativity, 19, 153-159. https://doi. org/10.1016/j.tsc.2015.10.009

Ward, T.B., Smith, S.M., \& Finke, R.A. (1999). Creative cognition. In: J.C. Kaufman \& R.J. Sternberg (Eds.), Handbook of Creativity, 189-212. Cambridge University Press.

Wasche, V. (2020, November 19). Women, don't turn your camera off for Zoom calls. Fast Company. https:// www.fastcompany.com/90577160/women-dont-turn-your-camera-off-for-zoom-calls

Weingart, L., Cronin, M., Houser, C., Cagan, J., \& Vogel, C. (2005). Functional diversity and conflict in crossfunctional product development teams: considering representational gaps and task characteristics. In L. Neider \& C. Schriesheim (Eds.), Understanding Teams (pp. 89-100). IAP.

Weingart, L.R., Todorova, G., \& Cronin, M.A. (2008). Representational gaps, team integration and team creativity. Paper Presented at the Academy of Management 2008 Annual Meeting: The Questions We Ask, AOM 2008, Briarcliff Manor, NY.

West, M.A., \& Anderson, N.R. (1996). Innovation in top management teams. Journal of Applied Psychology, 81(6), 680-693. https://doi.org/10.1037/0021-9010.81.6.680

White, M. (2014). The management of virtual teams and virtual meetings. Business Information Review, 31(2), 111-117. https://doi.org/10.1177\%2F0266382114540979

Zajac, S., Gregory, M.E., Bedwell, W.L., Kramer, W.S., \& Salas, E. (2014). The cognitive underpinnings of adaptive team performance in ill-defined task situations: A closer look at team cognition. Organizational Psychology Review, 4(1), 49-73. https://doi.org/10.1177/2041386613492787

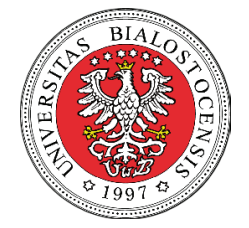

(c) Copyright by Faculty of Education, University of Bialystok,

20 Swierkowa St., 15-328 Bialystok, Poland

tel. +48857457283

e-mail: creativity@uwb.edu.pl

http://www.creativity.uwb.edu.pl 